\title{
ANALISIS KEKERASAN PERMUKAAN TITANIUM-6AI-4V PADA PROSES EDM SINKING DENGAN APLIKASI RESPONSE SURFACE METHODOLOGY (RSM)
}

\author{
Yuliyanto $^{1}$ \\ ${ }^{1}$ Jurusan Teknik Mesin - Politeknik Manufaktur Negeri Bangka Belitung \\ Kawasan Industri Airkantung Sungailiat, Telp.0717-93586, Fax.0717-93585, \\ belzanyuliyanto@yahoo.com,
}

\begin{abstract}
This study looked at the effect of severed EDM process parameters on the optimum value of titanium alloy hardness. this study uses Design Expert 9.0 software to help develop an experimental plan of response surface method models and CCD. The machine used is Hitachi Electrical Discharge Machining (EDM) brand with Series H-DSO2-S. Material used titanium 6Al-4V. Electrode used copper (Cu). The process parameters used are Current $(A)$, On time ( $\mu \mathrm{s})$ and Off time ( $\mu \mathrm{s})$. Coolant fluid using Hydroseal $63 \mathrm{H}$. The results of data processing there are 20 experiments. This research shows optimum machining condition for hardness (HV) is 322. Analysis of variance (Anova) shows the value of F arithmetic is 3,94, MSE is 0,022 and $p(0,0794)$. The increase of current and on-time values gives a great influence on surface roughness. The increase of Off time value does not give significant effect to the roughness. The next research will be done with 5 (five) process parameters, Current, On time, Off time, Machining Voltage and Servo feed.
\end{abstract}

Keywords: EDM Machine, Titanium 6Al-4V, RSM, Hardness

\begin{abstract}
Abstrak
Penelitian ini melihat pengaruh parameter proses EDM singking terhadap nilai optimum kekerasan paduan titanium. penelitian ini menggunakan perangkat lunak Design Expert 9.0 untuk membantu mengembangkan rencana eksperimen dari model metode permukaan respon dan CCD. Mesin yang digunakan adalah Electrical Discharge Machining (EDM) singking merk Hitachi dengan Series H-DSO2-S. Material yang digunakan titanium 6Al-4V. Elektroda yang digunakan tembaga (Cu). Parameter proses yang digunakan adalah Current $(A)$, On time $(\mu s)$ dan Off time ( $\mu \mathrm{s})$. Cairan pendingin menggunakan Hydroseal 63H. Hasil pengolahan data terdapat 20 kali percobaan. Penelitian ini menunjukan kondisi permesinan yang optimum untuk kekerasan (HV) adalah 322. Analisis variansi (Anova) menunjukan nilai $F$ hitung adalah 3,94, MSE yaitu 0,022 dan p (0,0794). Kenaikan nilai current dan on time memberikan pengaruh yang besar terhadap kekasaran permukaan. Kenaikan nilai Off time tidak memberikan pengaruh yang signifikan terhadap kekasaran. Penelitian selanjutnya akan dilakukan dengan 5 (lima) parameter proses yaitu Current, On time, Off time, Machining Voltage dan Servo feed.
\end{abstract}

Kata Kunci: Mesin EDM, Titanium 6Al-4V, RSM, Kekerasan

\section{PENDAHULUAN}

Electrical Discharge Machining (EDM) singking adalah salah satu proses pemesinan non konvensional yang tepat ketika pembuatan benda kerja dengan proses pemesinan konvensional sulit dilakukan. Proses ini telah digunakan secara efektif pada pemesinan material yang keras, berkekuatan tinggi, tahan terhadap suhu tinggi. Pada proses EDM, pemilihan variabel proses dalam mencapai kinerja pemesinan yang optimal sangat penting. Variabel proses pemesinan yang diinginkan ditentukan berdasarkan pengalaman dan buku pedoman. Selain itu proses EDM juga merupakan proses pemesinan dengan menggunakan proses erosi yang dihasilkan dari perbedaan potensial lewat sebuah Elektroda. Elektroda yang digunakan bisa terbuat dari tembaga, brass, zink, dll. Proses ini telah digunakan secara 
efektif pada pemesinan material yang keras, berkekuatan tinggi dan memiliki permukaan yang halus dan tingkat presisi yang tinggi [1]).

Beberapa penelitian telah dilakukan bahwa arus merupakan paktor yang paling signifikat terhadap MRR, arus dan pulsa on adalah parameter dominan dalam mempengaruhi kinerja proses [2\} MRR dipengaruhi oleh arus [3]. Penelitian lain yang berhubungan dengan parameter proses EDM bahwa Nilai rata-rata 0,27603 g / menit MRR, $0.00255 \mathrm{~g} /$ menit TWR dan 1,71 $\mu \mathrm{m}$ SR dengan parameter 5A arus, pulsa On time $8 \mu$ s dan pulsa off time $4 \mu$ s dengan bahan Inconel 800 [4] [7] [8]. Titanium (Ti) adalah logam struktur tahan korosi, ringan, kuat, termasuk tahan air laut dan chlorine dengan warna putih-metalik-keperakan dan memiliki kekerasan yang tinggi, biasanya digunakan dalam bentuk paduan (Titanium Alloy) untuk bagian konstruksi mesin pesawat da medis. Titanium dan paduan titanium menunjukkan ketahanan korosi yang luar biasa untuk air laut dan media air [5].

Pemotongan logam adalah proses manufaktur yang penting di dunia industri. Studi pemotongan logam berfokus pada tool yang digunakan, komposisi dan sifat mekanis benda kerja, serta semua parameter-parameter proses yang mempengaruhi efisiensi dan kualitas produk. Peningkatan efisiensi proses yang signifikan dapat diperoleh dengan mengoptimalkan parameter proses yang teridentifikasi. Daerah faktor kontrol proses kritis yang menghasilkan variasi produk atau respon dalam batas kriteria penerimaan yang memastikan biaya manufaktur lebih rendah [6]).

Penentuan kombinasi parameter proses dalam pembuatan produk-produk dengan beberapa target karakteristik kualitas yang kritis (Critical to Quality Characteristic/CTQ) cukup sulit dilakukan, karena kompleksitas yang dimiliki dan harus mengandalkan sejumlah besar rangkaian percobaan. Pemilihan dan penentuan variabel proses yang tepat untuk mencapai respon yang optimum sangat penting dilakukan secara efektif. Hal ini bertujuan untuk mengurangi proses trial and error, sehingga waktu dan biaya proses pemesinan menjadi efisien.

Umumnya, kekerasan menunjukan ketahanan terhadap deformasi dan merupakan ukuran ketahanan logam terhadap deformasi plastis atau deformasi permanen. Namun juga dalam dunia teknik mesin, kekerasan sering diartikan sebagai ukuran kemudahan dan kuantitas khusus yang menunjukan suatu kekuatan dan juga ketahanan dari suatu logam.

Penelitian ini direncanakan untuk mengekplorasi kondisi-kondisi optimum lainnya yang diharapkan dapat menghasilkan Kekerasan dan keakuratan hasil produk yang lebih baik.

\section{METODE PENELITIAN}

\subsection{TAHAPAN PENELITIAN}

Pelaksanaan penelitian dilakukan dengan beberapa tahap yang digunakan untuk pedoman penelitian, langkah awal dimulai dari studi-studi literatur yang didapat dari jurnal ilmiah. internet, handbook, text book, manual book. Selanjutnya data-data studi literature dipelajari dan dijadikan referensi untuk melakukan penelitian. Uraian langkah-langkah tersebut tertuang pada diagram alir gambar 1. 


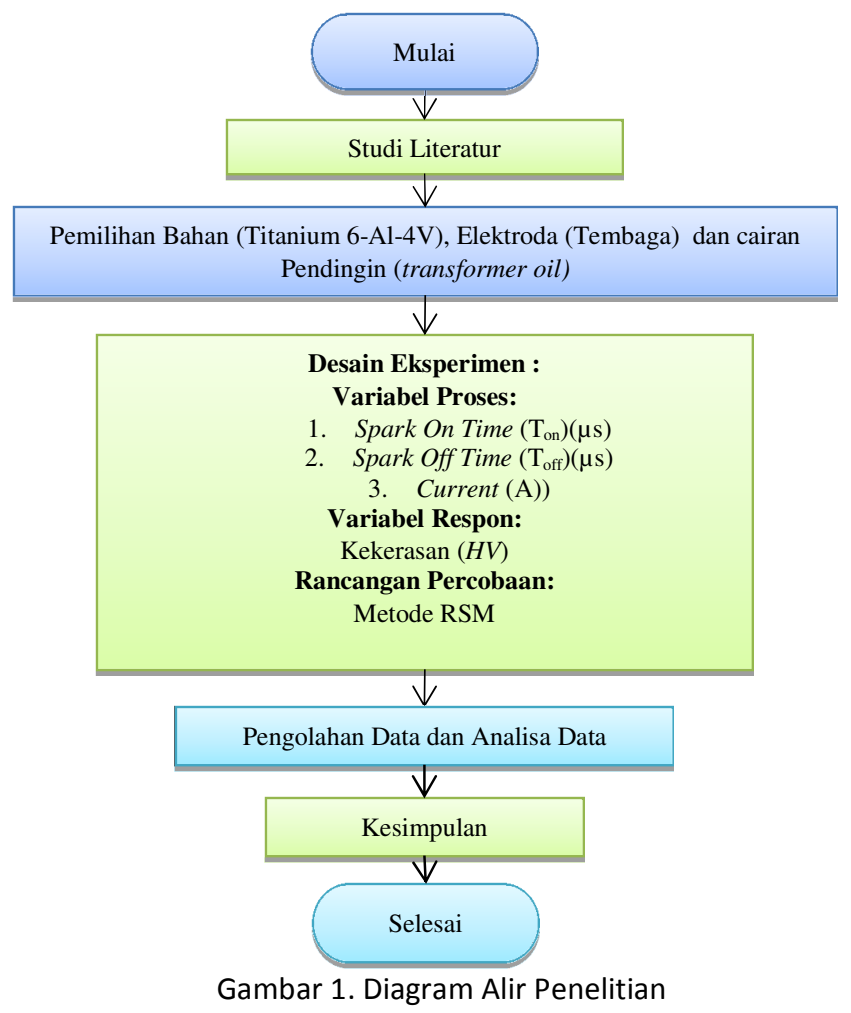

\subsection{BAHAN DAN ALAT PENELITIAN}

Bahan yang digunakan adalah Ti-6Al-4V (ASTM B381 Gr.5) dengan dimensi persegi, panjang 10 $\mathrm{mm}$, lebar $20 \mathrm{~mm}$, tinggi $11 \mathrm{~mm}$ Gambar 1(a). Komposisi bahan dapat dilihat pada Tabel 1. Pemilihan Ti6Al-4V sebagai benda kerja berdasar pada sifat utamanya yaitu: ulet dan keras. Bahan untuk elektroda atau pahat yang digunakan adalah tembaga (Gambar 1(b). Dasar pemilihan elektroda tembaga ini adalah:

1. Memiliki sifat konduktor yang baik.

2. Dapat digunakan untuk semua jenis logam.

\subsection{PERALATAN PENELITIAN}

Peralatan pengujian menggunakan mesin EDM sinking merk Hitachi dengan Series H-DSO2-S
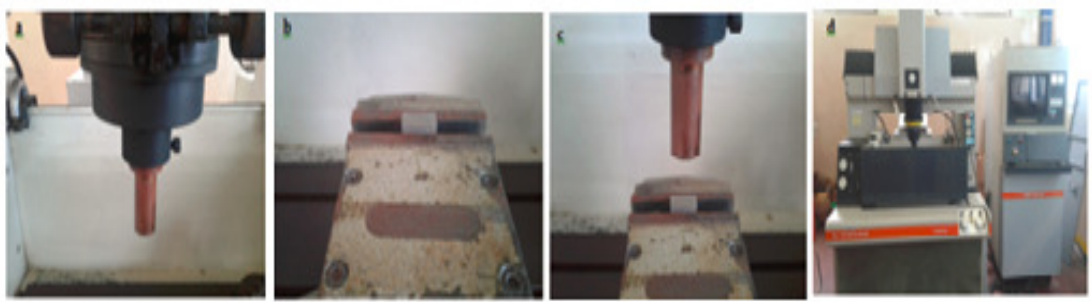

Gambar 3(a) Elektroda Tembaga (Cu), (b) Bahan Ti 6Al-4V, (c) posisi elektroda dan Bahan dan (d) Mesin EDM sinking (HITACHI H-DS $02 \mathrm{~S}$ )

\subsection{ALAT UKUR YANG DIGUNAKAN}

Alat ukur kekerasan (Microhardness Tester) yang digunakan adalah HT-1000A/HT-2000A. Alat ini digunakan untuk mengukur nilai kekerasan dari hasil pemotongan mengunakan EDM singking.

\subsection{ANALISA}

Analisa dilakukan dengan mengunakan metode permukaan respon, dimana akan dilihat pengaruh Ampere, pulse On dan pulse Off pada mesin EDM singking terhadap kekerasan Ti-6Al-4V serta 
pengaruh parameter lainnya. Berapakah nilai Optimum dari proses EDM singking untuk kekerasan yang baik pada Ti-6Al-4v agar Operator tidak melakukan proses EDM singking secara acak sesuai pengalaman yang diketahuinya.

\section{HASIL DAN PEMBAHASAN}

\subsection{HASIL PENGUJIAN}

Pengujian ini dilakukan untuk mengetahui pengaruh parameter pemotongan terhadap kekerasan permukaan (HV) Ti-6Al-4V menggunakan Mesin EDM singking. Data hasil pengujian selanjutnya diolah sehingga diperoleh kesimpulan dan menghasilkan nilai yang optimum (Tabel 2)

\begin{tabular}{|c|c|c|c|c|}
\hline No. & $\begin{array}{l}\text { Current } \\
\text { Ampere }\end{array}$ & $\begin{array}{c}\text { On Time } \\
\text { ys }\end{array}$ & $\begin{array}{c}\text { Off Time } \\
\text { us }\end{array}$ & $\begin{array}{c}\text { Kekerasan } \\
\text { MV }\end{array}$ \\
\hline 1 & 15 & 100 & 10 & 342 \\
\hline$=$ & 25 & 100 & 10 & $3,44,33$ \\
\hline 3 & 15 & 200 & 10 & 373 \\
\hline 4 & 25 & 200 & 10 & 375,33 \\
\hline 5 & 15 & 100 & 20 & 338,33 \\
\hline 6 & 25 & 100 & 20 & 334,67 \\
\hline 7 & 15 & $2 \infty$ & 20 & 372,67 \\
\hline 8 & 25 & 200 & 20 & 373,33 \\
\hline$=$ & 11.50 & 150 & 15 & 363,07 \\
\hline 10 & 28.41 & 150 & 15 & 365,67 \\
\hline 11 & 20 & 65.91 & is & 322,33 \\
\hline 12 & 20 & 234.09 & 15 & 378,67 \\
\hline 13 & 20 & 250 & 6.59 & 368,33 \\
\hline 14 & 20 & 150 & 23.41 & 362 \\
\hline is & 20 & 150 & $1 \mathrm{~s}$ & 363,07 \\
\hline 16 & 20 & 150 & 15 & ses \\
\hline 27 & 20 & 150 & 25 & 350,33 \\
\hline 28 & 20 & 150 & 25 & 363 \\
\hline 18 & 20 & 150 & 25 & 365 \\
\hline 20 & 20 & 150 & is & 363 \\
\hline
\end{tabular}

\subsection{Analisis Variansi Kekerasan Permukaan HV)}

Hasil perhitungan yang didapatkan pada lampiran 2, analisis variansi untuk kekerasan HV dapat ditabulasikan pada Tabel 3.

Tabel 3. ANOVA untuk Respon kekerasan Permukaan (HV)

\begin{tabular}{|c|c|c|c|c|c|c|}
\hline \multicolumn{7}{|c|}{ ANOVA for Resxonse Surface Quadratik model } \\
\hline Sourse & $\begin{array}{c}\text { Sum of } \\
\text { Squares }\end{array}$ & $\mathrm{df}$ & $\begin{array}{c}\text { Mean } \\
\text { Square }\end{array}$ & $\begin{array}{c}\mathrm{F} \\
\text { Value }\end{array}$ & $\begin{array}{l}\text { p-value } \\
\text { Prob > }\end{array}$ & \\
\hline Model & 4343,53 & 9 & 482,61 & 81,65 & $<0,0001$ & \\
\hline $\begin{array}{l}\text { A-Wire Fedd } \\
\text { (wf) }\end{array}$ & 1,85 & 1 & 1,85 & 0,31 & 0,5879 & significant \\
\hline$B-T_{\text {on }}$ & 3864,79 & 1 & 3864,79 & 653,82 & 0,0001 & \\
\hline C-Taff. & 50,72 & 1 & 50,72 & 8,58 & 0,0151 & \\
\hline $\mathrm{AB}$ & 2,35 & 1 & 2,35 & 0,4 & 0,5427 & \\
\hline $\mathrm{AC}$ & 7,35 & 1 & 7,35 & 1,24 & 0,2910 & \\
\hline $\mathrm{BC}$ & 15,13 & 1 & 15,13 & 2,56 & 0,1408 & \\
\hline$A^{\wedge} 2$ & 0,85 & 1 & 0,85 & 0,14 & 0,7120 & \\
\hline$B^{\wedge} 2$ & 397,51 & 1 & 397,51 & 67,25 & $<0,0001$ & \\
\hline $\mathrm{C}^{\wedge} 2$ & 0,064 & 1 & 0,064 & 0,011 & 0,9194 & \\
\hline Residual & 59,11 & 10 & 5.91 & & & \\
\hline Lack of Fit & 35,63 & 5 & 7,13 & 1,52 & 0,3292 & Not significant \\
\hline Pure Error & 23,48 & 5 & 4,7 & & & \\
\hline Cor Total & 4402,64 & 19 & & & & \\
\hline
\end{tabular}

Hasil Anova pada Tabel 3Error! Reference source not found. terlihat nilai $\mathrm{F}$ hitung (FModel $=$ $81,65)$ yang didapat pada tingkat signifikan sebesar 0,01 atau $1 \%$ dan nilai $p(<0,0001)$ memberikan nilai signifikan terhadap model yang ada. Sedangkan Lack of Fit yang terjadi tidak memberikan pengaruh (not significant) sehingga persamaan regresi model matematika dengan bentuk kuadratik yang digunakan dapat diterima.

\subsection{Permukaan Respon HV}

Grafik tiga dimensi (3D) untuk respon permukaan HV yang didapat dengan menggunakan bantuan perangkat lunak Disign Expert 9.0 dapat dilihat pada Gambar 5(a), dan Gambar 5(b). 


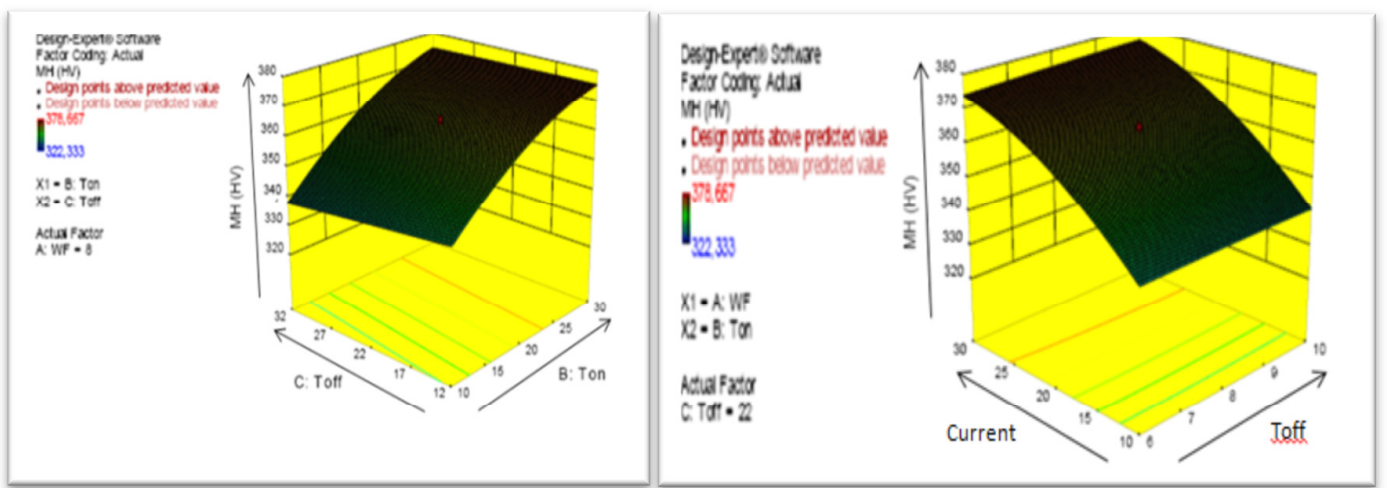

Gambar 5. Permukaan Respon Model Quadratik (a). HV vs Ton dan Current, (b). HV vs Current dan Toff

Permukaan respon grafik 3D untuk HV diatas dapat kita lihat bahwa, dari kenaikan nilai Ton. sangat signifikan dari $100 \mu$ s sampai ke $200 \mu \mathrm{s}$, dan juga current dengan kenaikan yang tidak sangat besar dari 15 A sampai ke 25 a. Ini dapat disimpulkan bahwa current memberikan dampak yang besar terhadap perubahan nilai kekerasan spesimen Sedangkan pengaruh Toff yang digunakan menunjukan penurunan nilai kekerasan. Hal ini dapat diartikan bahwa semakin besar Toff yang digunakan, maka kekerasan yang dihasilkan akan semakin besar. Hal ini berhubungan dengan proses pendinginan cepat, dimana ketika proses pemotongan akan terjadi panas yang tinggi dan pendingin langsung mendingikan benda kerja tersebut.

\section{SIMPULAN} kesimpulan:

Berdasarkan hasil percobaan dan pembahasan yang dilakukan, dapat diambil beberapa

Hasil kekerasan yang terkecil terdapat pada percobaan ke 11 dengan hasil 322,33 HV dengan parameter Ampere (current) $20 \mathrm{~A}, \mathrm{~T}_{\text {on }} 65.91 \mu \mathrm{s}$ dan $\mathrm{t}_{\text {off }} 15 \mu \mathrm{s}$, sedangkan hasil percobaan terbesar terdapat pada percobaan ke 12 dengan hasil 378,67 HV dengan parameter Ampere (current) $20 \mathrm{~A}, \mathrm{~T}_{\text {on }}$ $234.09 \mu \mathrm{s}$ dan $\mathrm{t}_{\text {off }} 15 \mu \mathrm{s}$. Hasil percobaan tersebut memberikan pengaruh terhadap Parameter proses, dimana current dan $\mathrm{T}_{\text {on }}$ memberikan pengaruh besar terhadap kekerasan permukaan. Kekerasan Permukaan yang besar disebabkan spark (ampere dan $\mathrm{T}_{\text {on }}$ ) yang telalu besar dan lama, sedangkan proses pendinginya $\left(t_{\text {off }}\right)$ terlalu cepat. Kekerasan yang kecil disebabkan spark (ampere dan Ton) yang kecil tetapi pendinginan lambat.

\section{DAFTAR PUSTAKA}

[1] Abdel, H. \& El-Hofy, G., Advanced Machining Processes. New York: McGraw Hill International, 2005.

[2] Abuthakeer,S.S et al, "Review of State of Art and Process Parameter Influence in EDM Technology", International Journal of Engineering Trends and Technology (IJETT), 48 (1): 39-47, 2017.

[3] Bose,G.K and Mahapatra,K, "Multi criteria decision making of machining parameters for Die Sinking EDM Process", International Journal of Industrial Engineering Computations, 6: 241-252, 2015.

[4] Karunakaran,K and Chandrasekaran,M, "Machineability Study On Die Sinking Edm Of Inconel 800 With Electrolyte Copper Electrode", ARPN Journal of Engineering and Applied Sciences, 12 (8): 24072411, 2017.

[5] Leyens, C. \& Peters, M., Titanium and Titanium Alloys : Fundamentals and Applications, Germany: Wiley-VCH , pp. ISBN 3-527-30534-3, 2003.

[6] Montgomery, D. C., Design And Analysis Of Experiment Eighth Edition. New York: Jhon Willey and Sons Inc, 2013.

[7] Ojha,K, Garg,R.K and Singh,K.K, “MRR Improvement in Sinking Electrical Discharge Machining: A Review", Journal of Minerals \& Materials Characterization \& Engineering, 9 (8): 709-739, 2010.

[8] Ali, M.A et al., "The Effect of Edm Die-sinking Parameters on Material Removal Rate of Beryllium Copper Using Full Factorial Method", Middle-East Journal of Scientific Research 16 (1): 44-50, 2013. 